\title{
Analisis Pengaruh Waktu Hidrolisis Terhadap Sifat Mekanis Selulosa Kristalin Dari Campuran Serbuk Gergaji Kayu Belian, Bengkirai, Jati dan Meranti \\ Neng Ayu Arini ${ }^{1)}$, Mariana Bara'allo Malino ${ }^{\text {*) }}$, Dwiria Wahyuni1)
}

\author{
1)Program Studi Fisika Jurusan Fisika FMIPA Universitas Tanjungpura \\ Jl.Prof.Dr.H.Hadari Nawawi Pontianak \\ *Email: marianabaraallomalino@physics.untan.ac.id
}

\begin{abstract}
Abstrak
Telah dilakukan penelitian untuk menganalisis pengaruh waktu hidrolisis terhadap sifat mekanis selulosa kristalin dari campuran serbuk gergaji kayu belian, bengkirai, jati dan meranti. Isolasi selulosa kristalin dari serbuk gergaji dilakukan melalui 3 tahap yaitu ekstraksi, bleaching dan hidrolisis asam. Tahap ekstraksi menggunakan larutan alkohol-benzena (1:2) dan larutan $\mathrm{NaOH}$ dengan $\mathrm{Na}_{2} \mathrm{~S}$. Tahap bleaching menggunakan hipoklorit 30\%. Sedangkan tahap hidrolisis asam menggunakan $\mathrm{HCl} 37 \%$ dengan asam: selulosa yaitu 4:1. Selulosa kristalin dibuat dengan variasi waktu hidrolisis yaitu 30 menit, 45 menit dan 90 menit. Nilai optimum diperoleh dari hasil hidrolisis 30 menit dengan derajat kristalinitas $74,49 \%$, kekuatan tarik 20,09 kPa, kekuatan putus 17,64 kPa dan modulus elastisitas 1,3393 MPa. Nilai derajat kristalinitas berbanding lurus dengan parameter mekanis selulosa kristalin yang dihasilkan.
\end{abstract}

Kata Kunci: Selulosa kristalin, Derajat kristalinitas, Kekuatan tarik, Kekuatan putus, Modulus elastisitas

\section{Latar Belakang}

Produksi total kayu gergajian Indonesia mencapai 2,6 juta $\mathrm{m}^{3}$ pertahun. Dengan asumsi bahwa jumlah limbah yang terbentuk adalah $54,24 \%$ dari produksi total maka limbah penggergajian kayu yang dihasilkan sebanyak 1,4 juta $\mathrm{m}^{3}$ pertahun. Angka tersebut relatif besar karena mencapai sekitar separuh dari produksi kayu gergajian (Pari, 2002). Limbah kayu pada industri penggergajian terdiri dari serbuk gergaji, sebetan dan potongan ujung.

Serbuk gergaji dapat dimanfaatkan sebagai bahan bakar misalnya briket arang (Wijayanti, 2009) tetapi pembuatan briket arang dari serbuk gergaji memerlukan volume dan temperatur proses yang relatif tinggi. Serbuk gergaji memiliki kandungan selulosa sekitar 40\% (Arias dan Elsa, 2011) yang berpotensi untuk dimanfaatkan sebagai bahan pengisi. Pemanfaatan serbuk gergaji sebagai bahan pengisi lebih efisien dibanding sebagai bahan bakar, karena memerlukan volume dan temperatur proses yang relatif rendah. Lestari (2011) telah melakukan penelitian mengenai komposit karet alam dan selulosa kristalin dari serbuk gergaji. Palangan (2007) menghasilkan komposit yang diisi serbuk gergaji kayu belian dengan kekuatan tarik sebesar 28,91 MPa.

Sifat mekanis merupakan parameter penting bagi penentuan kualitas suatu material sebagai bahan pengisi. Rosa, dkk (2009) mengatakan bahwa penurunan waktu hidrolisis meningkatkan derajat kristalinitas selulosa nanokristalin dari serat kelapa. Nilai kekuatan tarik polipropilena semakin besar apabila derajat kristalinitas yang dihasilkan semakin besar (Sudirman, 2004).

Penelitian dilakukan dengan memanfaatkan serbuk gergaji sebagai sumber selulosa kristalin dari 4 jenis kayu keras yakni kayu belian (Eusideroxylon zwageri), bengkirai (Shorea leavis ridl), jati (Tectona grandis l.f) dan meranti (Shorea sp.) yang dapat mengurangi volume limbah serbuk gergaji. Jadi pengolahan serbuk gergaji sebagai sumber selulosa kristalin dapat meningkatkan nilai tambah bagi hasil sampingan dalam pengolahan kayu dan produk kayu. Penelitian dilakukan dengan memvariasikan waktu hidrolisis asam pada serbuk gergaji untuk mengetahui pengaruh waktu hidrolisis pada sifat mekanis selulosa kristalin yang dihasilkan.

\section{Metodologi}

Alat dan Bahan

Alat-alat yang digunakan adalah ayakan 200 mesh, botol vial ukuran $150 \mathrm{~mL}$, corong, flexure machine, gelas ukur, grindstone machine, kertas saring, kurs porselen, neraca digital, oven pemanas, pengaduk gelas, pipet ukur, plastik wrapping, refrigerator, sentrifugator, sieve shaker, sonikator, universal testing machine dan $\mathrm{XRD}$. Bahan-bahan yang digunakan adalah alkohol $\left(\mathrm{C}_{2} \mathrm{H}_{5} \mathrm{OH}\right)$ teknis, akuades $\left(\mathrm{H}_{2} \mathrm{O}\right)$, benzena $\left(\mathrm{C}_{6} \mathrm{H}_{12}\right)$ p.a., hipoklorit (HCO) teknis $30 \%$, hydrochloric acid ( $\mathrm{HCl})$ p.a. $37 \%$, natrium hidroksida $(\mathrm{NaOH})$ p.a., natrium sulfida $\left(\mathrm{Na}_{2} \mathrm{~S}\right)$ p.a. dan serbuk gergaji (kayu belian, bengkirai, jati dan meranti). 


\section{Ekstraksi serbuk gergaji}

Serbuk gergaji sebanyak 500 gram (125 gram untuk setiap 4 jenis kayu) yang sudah bersih dan lolos ayakan 200 mesh diekstraksi dengan alkohol-benzena (1:2) selama 4 jam dan dioven pada suhu $80^{\circ} \mathrm{C}$ kemudian diturunkan menjadi suhu $40^{\circ} \mathrm{C}$ sampai sampel kering. Serbuk dibilas dengan air panas dan air dingin lalu dilarutkan dengan $\mathrm{NaOH}$ dan $\mathrm{Na}_{2} \mathrm{~S}$ selama 2 jam. Residu dilarutkan lagi dengan $\mathrm{NaOH}$ panas selama 1 jam sebanyak 2 kali kemudian dikeringkan ke dalam oven dengan suhu $65^{\circ} \mathrm{C}$ selama 1 jam.

\section{Pemutihan (Bleaching)}

Bleaching dilakukan dengan merendam sampel ke dalam larutan $\mathrm{NaOH} 1$ gram dan hipoklorit 30\% selama 30 menit, proses dilakukan sebanyak 3 kali kemudian disaring dan dibiarkan pada suhu kamar.

\section{Hidrolisis selulosa}

Selulosa dihidrolisis menggunakan $\mathrm{HCl}$ 37\% melalui pengadukan pada suhu $45^{\circ} \mathrm{C}$ dengan lama waktu hidrolisis 30 menit, 45 menit, 90 menit dan perbandingan asam:selulosa yaitu 4:1. Selulosa dikeringkan dan disentrifugasi pada 10.000 rpm selama 1 jam lalu disonifikasi selama 30 menit. Selulosa didinginkan dalam refrigerator selama 24 jam kemudian disaring dan dikeringkan dalam oven.

\section{Pembuatan lembaran selulosa kristalin}

Selulosa kristalin dimasukkan ke dalam cetakan dan dikempa pada tekanan $32 \mathrm{MPa}$ menggunakan flexure machine. Lembaran selulosa kristalin kemudian dipotong dengan ukuran panjang $5 \mathrm{~cm}$ dan lebar $2 \mathrm{~cm}$.

\section{Karakterisasi selulosa kristalin Uji derajat kristalinitas}

Derajat kristalinitas ditentukan berdasarkan persamaan 1 (Wang, dkk., 2009).

$$
\chi=\frac{I_{\overline{1} \overline{1} 2}-I_{0}}{I_{\overline{1} \overline{1} 2}} \times 100 \%
$$

dengan $\chi$ adalah derajat kristalinitas (\%), $I_{\text {T12 }}$ adalah intensitas puncak dan $I_{0}$ adalah intensitas minimum dari $I_{112}$.

\section{Uji mekanis}

Hasil uji tarik selulosa kristalin untuk menentukan parameter mekanis. Kekuatan tarik (yield strength) diperoleh berdasarkan persamaan 2 (Lestari, 2011).

$$
\sigma_{y}=\frac{F_{\max }}{A}
$$

dengan $\sigma_{\mathrm{y}}$ adalah kekuatan tarik $(\mathrm{Pa}), \mathrm{F}_{\max }$ adalah gaya pembebanan maksimum $(\mathrm{N})$ dan $\mathrm{A}$ adalah luas permukaan $\left(\mathrm{m}^{2}\right)$.

Kekuatan putus ditentukan dengan persamaan 3.

$$
T S=\frac{F_{\text {breaking }}}{A_{0}}
$$

dengan TS adalah kekuatan putus (Pa), $F_{\text {breaking }}$ adalah beban saat benda uji putus $(\mathrm{N})$ dan $\mathrm{A}_{0}$ adalah luas permukaan awal $\left(\mathrm{m}^{2}\right)$.

Tegangan diperoleh dari persamaan 4 .

$$
\sigma=\frac{F}{A}
$$

dengan $\sigma$ adalah tegangan (Pa), $\mathrm{F}$ adalah gaya beban $(\mathrm{N})$ dan A adalah luas permukaan $\left(\mathrm{m}^{2}\right)$. Regangan dihasilkan oleh persamaan 5 .

$$
\varepsilon=\frac{\delta}{L_{0}}=\frac{\Delta L}{L_{0}}
$$

dengan $\varepsilon$ adalah regangan, $\delta$ adalah perubahan panjang $(\mathrm{m}), \mathrm{L}_{0}$ adalah panjang mula-mula $(\mathrm{m})$ dan $\Delta \mathrm{L}$ adalah pertambahan panjang $(\mathrm{m})$.

Berdasarkan persamaan (4) dan (5) maka modulus elastisitas ditentukan melalui persamaan 6 .

$$
E=\frac{\sigma}{\varepsilon}
$$

dengan $\mathrm{E}$ adalah modulus elastisitas $(\mathrm{Pa}), \sigma$ adalah tegangan $(\mathrm{Pa})$ dan $\varepsilon$ adalah regangan.

\section{Hasil dan Pembahasan Isolasi Selulosa Kristalin Ekstraksi serbuk gergaji}

Proses ekstraksi bertujuan untuk membersihkan senyawa kimia kayu dari zat ekstraktif seperti lemak, resin dan minyak. Keberhasilan proses ditandai dengan perubahan warna sampel yang dialami yaitu semakin cerah. Proses ekstraksi serbuk gergaji ditunjukkan pada Gambar 1.

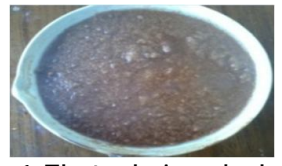

Gambar 1 Ekstraksi serbuk gergaji

Proses pelarutan serbuk ke dalam $\mathrm{NaOH}$ dan $\mathrm{Na}_{2} \mathrm{~S}$, kemudian dilanjutkan lagi dengan $\mathrm{NaOH}$ bertujuan untuk menghilangkan senyawa kimia kayu yakni hemiselulosa yang terkandung di dalam serbuk gergaji. Reaksi yang terjadi antara selulosa dan $\mathrm{NaOH}$ adalah:

$\mathrm{C}_{6} \mathrm{H}_{10} \mathrm{O}_{5(\mathrm{~s})}+\mathrm{NaOH}_{(\mathrm{aq})} \rightarrow \mathrm{C}_{6} \mathrm{H}_{9} \mathrm{O}_{5} \mathrm{Na}_{(\mathrm{s})}+\mathrm{H}_{2} \mathrm{O}_{(\mathrm{l})}$

Permukaan selulosa mengalami perubahan kimia yaitu pertukaran ion $\mathrm{H}$ - dari molekul selulosa dengan ion $\mathrm{Na}^{+}$sehingga mereduksi gugus hidroksil $(\mathrm{OH})$ yang menghasilkan selulosa mudah larut dalam air dan $\mathrm{C}_{6} \mathrm{H}_{9} \mathrm{O}_{5} \mathrm{Na}$ merupakan selulosa alkali yang membantu proses bleaching karena bersifat basa.

\section{Pemutihan (Bleaching) serbuk gergaji}

Bleaching bertujuan untuk menghilangkan zat warna pada serbuk gergaji yang berasal dari lignin. Proses bleaching menggunakan pemutih yaitu hipoklorit karena mengandung oksidator 
yang kuat sehingga bisa menghilangkan lignin. Bleaching dibantu dengan penambahan $1 \mathrm{gram}$ $\mathrm{NaOH}$ untuk mempercepat bleaching. Proses bleaching serbuk gergaji dilihat pada Gambar 2.

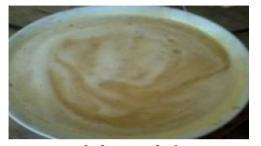

Gambar 2 Proses bleaching serbuk gergaji

\section{Hidrolisis selulosa}

Selulosa kristalin dapat diperoleh dengan cara hidrolisis asam yaitu proses menghilangkan daerah amorf dari selulosa. HCl merusak sisasisa lignin yang terdapat pada serbuk gergaji. Selulosa yang dikehendaki yakni selulosa $\alpha$ yang berbentuk kristalin berada di dalam sel lignin sehingga sel lignin perlu dirusak untuk mengisolasi selulosa di dalam lignin. Hidrolisis selulosa kristalin dapat dilihat pada Gambar 3.

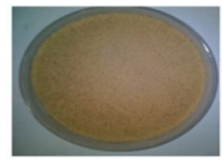

(a)

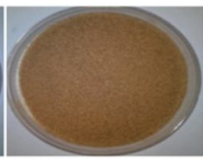

(b)

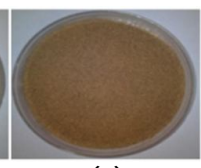

(c)
Gambar 3 Hidrolisis selulosa kristalin

(a) 30 menit (b) 45 menit (c) 90 menit

Selulosa yang sudah dihidrolisis akan menghasilkan selulosa kristalin. Hasil cetakan selulosa kristalin ditunjukkan pada Gambar 4.

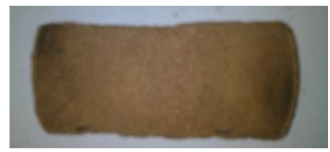

Gambar 4 Hasil cetakan selulosa kristalin

\section{Karakterisasi XRD}

Karakterisasi XRD bertujuan untuk menentukan derajat kristalinitas selulosa kristalin. Hasil karakterisasi XRD selulosa kristalin dari serbuk gergaji dapat ditunjukkan pada Gambar 5, sedangkan hasil derajat kristalinitas selulosa kristalin dari serbuk gergaji dapat dilihat pada Tabel 1.
Tabel 1 Derajat kristalinitas selulosa kristalin dari serbuk gergaji

\begin{tabular}{cc}
\hline $\begin{array}{c}\text { Waktu Hidrolisis } \\
\text { (menit) }\end{array}$ & $\begin{array}{c}\text { Derajat Kristalinitas } \\
(\%)\end{array}$ \\
\hline 30 & 74,49 \\
45 & 71,27 \\
90 & 70,16 \\
\hline
\end{tabular}

Derajat kristalinitas sebesar 74,49\% menunjukkan bahwa struktur rantai selulosa pada hidrolisis 30 menit lebih teratur dibandingkan hasil hidrolisis pada 45 menit dan 90 menit, sehingga derajat kristalinitas yang dihasilkan besar. Struktur rantai selulosa pada hidrolisis 45 menit mengalami deformasi yaitu terjadi pemutusan rantai antar selulosa sehingga rantai selulosa menjadi tidak teratur. Struktur rantai selulosa pada hidrolisis 90 menit juga mengalami deformasi dan semakin tidak teratur. Ketidakteraturan dikarenakan penggunaan $\mathrm{HCl}$ selama 90 menit mengindikasikan terjadi pembukaan susunan rantai selulosa sehingga mengubah susunan rantai polimer dan selulosa lebih mudah terdegradasi menjadi glukosa. Struktur rantai selulosa kristalin dapat dilihat pada Gambar 6.

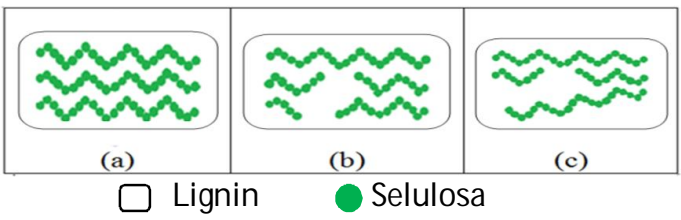

Gambar 6 Struktur rantai selulosa alfa

(a) 30 menit (b) 45 menit (c) 90 menit

Ketidakteraturan mempengaruhi hasil derajat kristalinitas yang dihasilkan karena semakin teratur rantai selulosa maka derajat kristalinitas selulosa kristalin semakin besar.

\section{Parameter Mekanis Selulosa kristalin}

Kekuatan tarik cenderung mengalami penurunan seiring dengan kenaikan waktu hidrolisis seperti ditunjukkan pada Tabel 2 .

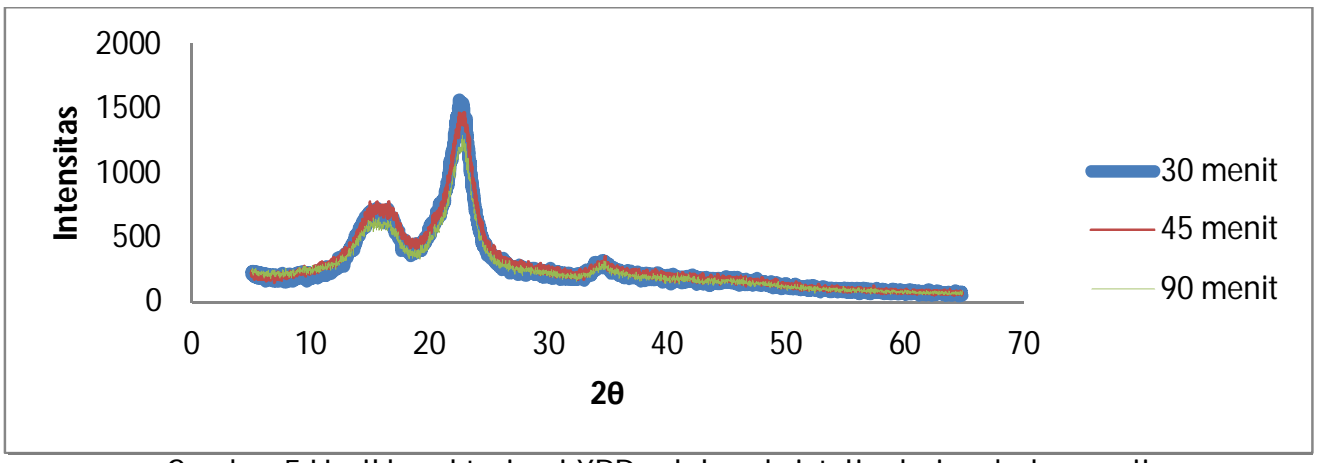

Gambar 5 Hasil karakterisasi XRD selulosa kristalin dari serbuk gergaji 
Tabel 2 Kekuatan tarik selulosa kristalin dari serbuk gergaji

\begin{tabular}{cc}
\hline $\begin{array}{c}\text { Waktu Hidrolisis } \\
\text { (menit) }\end{array}$ & $\begin{array}{c}\text { Kekuatan Tarik Rerata } \\
(\mathrm{kPa})\end{array}$ \\
\hline 30 & 20,09 \\
45 & 16,66 \\
90 & 11,76 \\
\hline
\end{tabular}

Proses isolasi pada hidrolisis 30 menit menghasilkan derajat kristalinitas yang besar yaitu $74,49 \%$ dan menghasilkan kekuatan tarik sebesar 20,09 kPa. Hal tersebut dikarenakan oleh kekuatan tarik berbanding lurus dengan derajat kristalinitas. Nilai kekuatan tarik memberikan gaya maksimum yang bertujuan mengetahui ketahanan selulosa kristalin dalam menahan gaya yang diberikan. Ketahanan selulosa kristalin dihasilkan dari ikatan antar rantai selulosa yang kuat.

Tabel 3 Kekuatan putus selulosa kristalin dari serbuk gergaji

\begin{tabular}{cc}
\hline $\begin{array}{c}\text { Waktu Hidrolisis } \\
\text { (menit) }\end{array}$ & $\begin{array}{c}\text { Kekuatan Putus Rerata } \\
(\mathrm{kPa})\end{array}$ \\
\hline 30 & 17,64 \\
45 & 14,21 \\
90 & 9,31 \\
\hline
\end{tabular}

Kekuatan putus cenderung mengalami penurunan seiring dengan kenaikan waktu hidrolisis seperti ditunjukkan pada Tabel 3. Hal tersebut dikarenakan oleh keteraturan rantai selulosa yang mempengaruhi kekuatan putus. Semakin teratur rantai selulosa maka daerah amorf semakin kecil dan daerah kristal semakin besar. Hal tersebut menyebabkan derajat kristalinitas yang dihasilkan semakin besar. Susunan rantai selulosa yang semakin teratur mengakibatkan pemberian gaya breaking semakin besar agar selulosa kristalin putus.

Tabel 4 Tegangan, tegangan dan modulus elastisitas selulosa kristalin dari serbuk gergaji

\begin{tabular}{cccc}
\hline $\begin{array}{c}\text { Waktu } \\
\text { Hidrolisis } \\
\text { (menit) }\end{array}$ & $\begin{array}{c}\text { Tegangan } \\
\text { Rerata } \\
(\mathrm{kPa})\end{array}$ & $\begin{array}{c}\text { Regangan } \\
\text { Rerata }\end{array}$ & $\begin{array}{c}\text { Modulus } \\
\text { elastisitas } \\
\text { Rerata } \\
(\mathrm{MPa})\end{array}$ \\
\hline 30 & 20,09 & 0,015 & 1,33933 \\
45 & 16,66 & 0,016 & 1,04125 \\
90 & 11,76 & 0,019 & 0,61895 \\
\hline
\end{tabular}

Modulus elastisitas cenderung mengalami penurunan pada saat penambahan waktu hidrolisis yang dikarenakan oleh semakin banyak selulosa yang tidak teratur, hal ini dapat dilihat dari hasil derajat kristalinitas selulosa kristalin yang rendah seperti ditunjukkan pada Tabel 4.

\section{Kesimpulan}

1. Proses isolasi selulosa kristalin dari serbuk gergaji melalui 3 tahap yaitu ekstraksi, bleaching dan hidrolisis asam.

2. Nilai derajat kristalinitas, kekuatan tarik, kekuatan putus dan modulus elastisitas cenderung berbanding terbalik terhadap waktu hidrolisis asam. Waktu hidrolisis optimum adalah selama 30 menit, yaitu dengan derajat kristalinitas sebesar 74,49\%, kekuatan tarik sebesar 20,09 kPa, kekuatan putus sebesar 17,64 $\mathrm{kPa}$ dan modulus elastisitas sebesar 1,3393 MPa.

\section{Daftar Pustaka}

Arias, G. dan Elsa A., 2011, Variasi Kondisi Operasi Steam Pretreatment Sawdust (Serbuk Kayu) sebagai Bahan Baku Produksi Glukosa, ITS, Surabaya. Skrpsi.

Lestari, S., 2011, Analisis Sifat Mekanis dan Viskositas Mooney Komposit Karet AlamSelulosa Kristalin, Universitas Tanjungpura, Pontianak. Skripsi.

Palangan, W., 2007, Pengaruh Jenis Serbuk Kayu terhadap Sifat Mekanik Komposit Polyethylene/ Serbuk Kayu, Fakultas Teknologi Industri, ITS. Surabaya. Skripsi.

Pari, 2002, Forestry statistic of Indonesia. Secretary General of Forestry 1997/1998, Ministry of Forestry and Estate Crops, Bureau of Planning, Jakarta.

Rosa, M. F., E. S. Medeiros, J. A. Malmonge, D. F. Wood, L. H. C. Mattoso, W. J. Orts, dan S. H.Imam, 2009, Nanocomposites Based on Natural Rubber and Cellulose Nanocrystals from Coconut Fibers, The 11th International Conference on Advanced Materials, Rio de Janeiro, Brazil.

Sudirman, 2004, Analisis Sifat Kekuatan Tarik, Derajat Kristalinitas dan Struktur Mikro Komposit Polimer Polipropilena-Pasir, Jurnal sains materi Indonesia, 1-6, issn:1411-1098.

Wang, K., Jiang, J.X., Xu, F., dan Sun, R.C., 2009, Influence of steaming pressure on steam explosion pretreatment of Lespedeza stalks (Lespedeza crytobotrya): Part1. Characteristics of degraded cellulose, Polym. Degrad. Stabil. 94, 1379-1388.

Wijayanti, D.S., 2009, Karakteristik Briket Arang dari Serbuk Gergaji dengan Penambahan Arang Cangkang Kelapa Sawit, Fakultas Pertanian, Universitas Sumatra Utara. Skripsi. 